
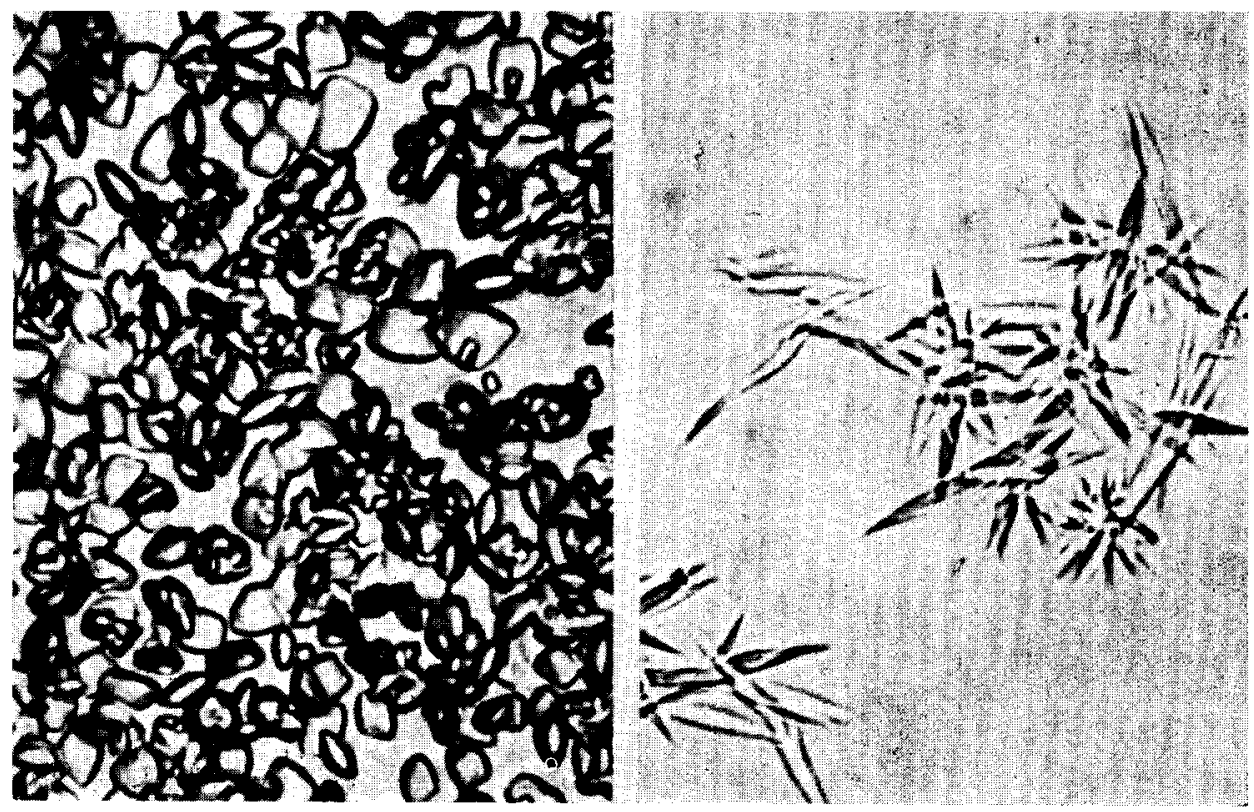

Fig. 1. Heat stable muscle protein. (Magnification $850 \times$ )

tation rate of very elongated particles depends primarily on width and very little on length, the homogeneity suggested by a sharp sedimenting boundary may be illusory, and the results compatible with the assumption that the material consists of thread-like particles of uniform width, in various degrees of linear aggregation. Osmotic pressure measurements by the senior author's method yielded only erratic results, a fact usually observed with material that can be suspected of physical instability.

JAQUES BOURDILLON Division of Labovatories and Research, New York State Department of Health, WINFIELD H. BAKER Albany, N.Y. (U.S.A.)

1 J. T. Edsall, in The Proteins, edited by H. Neurath and K. Batley, Academic Press, Inc., New York, I953, Vol. I, Part B, p. 689 (Table).

2 T. Svedberg And K. O. Pedersen, The Ultracentrifuge, Clarendon Press, Oxford, 1940, p. $4^{\mathrm{I}}$ (Table)

3 A. R. Peacocke and H. K. Schachman, Biochim. Biophys. Acta, I5 (1954) Ig8.

4 A. Szent-Györgyi, Chemistry of Muscular Contraction, Academic Press, Inc., New York, I951, and ed.

5 J. Bourdillon, Arch. Biochem., I6 (1948) 6I

$6 \mathrm{~J}$. Bourdillon, J.Am. Chem. Soc. (in press).

7 J. Bourdillon, J. Biol. Chem., r27 (r939) 6r.7.

Received November $5^{\text {th, }}$ I955

\title{
Synthesis of ribose by the rat*
}

The biosynthesis of ribose ${ }^{1}$ has been postulated to occur (a) directly from hexose by loss of an end carbon and (b) from smaller units by condensation, e.g. $\mathrm{C}_{2}+\mathrm{C}_{3}$. Data obtained in previous experiments ${ }^{2}$ have been interpreted to indicate that in the chick, the synthesis of this pentose probably occurs by the latter mechanism, possibly by a condensation of glyceraldehyde3-phosphate and an active $\mathrm{C}_{2}$ unit (e.g. from fructose-6-phosphate ${ }^{3}$ ) catalyzed by transketolase. The technique employed was to isolate glycogen and ribose from the combined internal organs

* Presented at the meeting of the American Chemical Society, Cincinnati, Ohio, April, I955. 
of chiks after the administration of ${ }^{14} \mathrm{C}$-labeled precursors and to compare the patterns of ${ }^{14} \mathrm{C}$ in the two carbohydrates. If ribose were synthesized from hexose directly, the pattern of ${ }^{14} \mathrm{C}$ in the ribose should be similar to that of five consecutive carbons in the hexose. Dissimilar patterns would indicate the probable existence of another mechanism. The patterns of ${ }^{14} \mathrm{C}$ in the glycogen and ribose isolated from the tissues of the chicks were markedly different and it was concluded that the data were consistent with the hypothesis that the pentose arose by combination of $\mathrm{C}_{2}$ and $\mathrm{C}_{3}$ units. The applicability of this conclusion to other organisms was then investigated using the same technique.

In Escherichia coli, strain B, as suggested by LANNING AND COHEN ${ }^{4}$, ribose appears to be synthesized primarily from hexose by loss of carbon $I^{5}$. In the rat, however, the data indicate that the direct pathway from hexose is not the only mechanism for the synthesis of the pentose. When rats were given $\mathrm{NaH}^{14} \mathrm{CO}_{3}$ and ribose and glycogen were isolated from the liver, the distribution of ${ }^{14} \mathrm{C}$ in the two carbohydrates were dissimilar.

Rats (about $300 \mathrm{~g}$ each) were starved for 48 hours and given intraperitoneally a total of I.4 ${ }^{1} \mathrm{O}^{9}$ c.p.m. per Ioo g body weight of $\mathrm{NaH}^{14} \mathrm{CO}_{3}(\mathrm{I} .23 \mathrm{~m} M)$ in equal doses at $0,0.5, \mathrm{I}, 2,2.5 .3 .5$ and 4 hours and by stomach tube $200 \mathrm{mg}$ of glucose at o time. At 4.5 hours, the animals were sacrificed and the ribose (from ribonucleic acid) and the glycogen were isolated from the pooled livers by the methods previously described2. After hydrolysis of the glycogen, the resulting glucose was purified by filter paper chromatography, diluted 97 fold with unlabeled glucose and recrystallized ${ }^{6}$. The pattern of radioactivity in the hexose was determined by fermentation with Leuconostoc mesenteroides ${ }^{\star}{ }^{\star}$. The ribose was also purified by paper chromatography ${ }^{2}$ and after a $45^{\circ}$ fold dilution with carrier was degraded for analysis of ${ }^{14} \mathrm{C}$ by fermentation with Lactobacillus pentosus ${ }^{\star \star \star}$. Radioactivity data for the individual carbons, obtained by gas phase counting ${ }^{8}$, are presented in specific activities relative to that determined for one of the carbons given a value of Ioo.

The relative specific activities found were as follows ${ }^{\star \star *}$ :

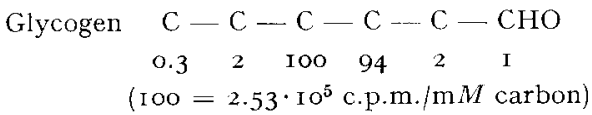

$$
\begin{aligned}
& \text { Ribose } \mathrm{C}-\mathrm{C}-\mathrm{C}-\mathrm{C}-\mathrm{CHO} \\
& \begin{array}{lllll}
2 & 5 & 100 & 49 & 22
\end{array} \\
& \text { ( } 100=\mathrm{I} \cdot 16 \cdot 10^{3} \text { c.p.m. } / \mathrm{m} M \text { carbon) }
\end{aligned}
$$

The author wishes to express his appreciation to Miss Dorothy Sweet and Miss PhyLlis Foster for extremely cooperative technical assistance and to Dr. ARTHUR C. CURTIS for his interest in the continuation of this work.

I. A. BERNSTEIN

Department of Dermatology, School of Medicine and the Institute of Industrial Health, University Hospital,

University of Michigan, Ann Arbor, Mich. (U.S.A.)

I For reviews of this subject see S. S. Cohen, in D. M. Greenberg, Chemical Pathways of Metabolism, Academic Press, New York, Vol. I, page 173, 1954, and G. E. Glock, in E. Chargaff AND J. N. Davidson, The Nucleic Acids, Academic Press, New York, Vol. II, page 248, 1955. 2 I. A. Bernstein, J. Biol. Chem., 205 (I955) 317.

3 E. Racker, G. de la Haba and J. G. Leder, Arch. Biochem. Biophys., 48 (I954) 238.

4 M. C. Lanning and S. S. Cohen, J. Biol. Chem., 207 (I954) I93.

5 I. A. Bernstein, unpublished.

6 I. A. Bernstein, K. Lentz, M. Malm, P. Schambye and H. G. Wood, J. Biol. Chem., 2 I5 (1955) I 37.

7 I. A. Bernstein, J. Biol. Chem., 205 (I955) 309.

8 W. Bernstein and R. Ballentine, Rev. Sci. Instr., 2 I (1950) 158.

Received October 6th, 1955

* Specific activity determinations on the recrystallized product indicated $5 \cdot 19 \cdot 10^{5}$ c.p.m. $/ \mathrm{m} M$ of glucose. Potassium gluconate prepared from this material contained $5.05 \cdot 10^{5}$ c.p.m. $/ \mathrm{m} M$ of compound. Fermentation data showed $5.08 \cdot 10^{5}$ c.p.m. $/ \mathrm{m} M$ of hexose.

$\star \star$ Potassium ribonate prepared from the diluted material contained 2, I5o c.p.m./mM of compound. Fermentation data indicated a specific activity of 2,060 c.p.m./mM of pentose.

$\star \star \star$ The specific activities shown for the carbons given a value of Ioo represent the levels at which the determinations were actually made on the diluted samples. 